\title{
Effect of microwave irradiation for crystallization behavior of yttria-stabilized zirconia system
}

\author{
Masashi YOSHINAGA ${ }^{1,2, \dagger}$, Takashi SASAKI ${ }^{1}$ and Naoto KOBAYASHI ${ }^{1}$ \\ ${ }^{1}$ Department of Prime Mover Engineering, School Engineering, Tokai University, \\ 4-1-1 Kitakaname, Hiratsuka, Kanagawa 259-1292, Japan \\ ${ }^{2}$ Course of Mechanical Engineering, Graduate School of Engineering, Tokai University, \\ 4-1-1 Kitakaname, Hiratsuka, Kanagawa 259-1292, Japan
}

The yttria-stabilized zirconia precursors of $x$ mol\% $\mathrm{Y}_{2} \mathrm{O}_{3} /(100-x)$ mol\% $\mathrm{ZrO}_{2}$ was successfully synthesized by homogeneous precipitation method by microwave heating. The Raman spectroscopy and Fourier Transform Infrared Spectroscopy (FT-IR) measurements clarified that the precursor contained zirconium hydroxide. The crystallization behaviors of the precursor were investigated by the X-ray diffraction, Raman spectroscopy, FTIR, and Differential Scanning Calorimetry (DSC) measurements. For the FT-IR measurements only Zr-O bond was appeared at $500^{\circ} \mathrm{C}$. By the DSC measurements revealed that the crystallization temperature of the precursor with microwave heating was lower, and the density was higher than that of conventional heating. This advance could cause by microwave technique.

(C2019 The Ceramic Society of Japan. All rights reserved.

Key-words : Yttria stabilized zirconia, Precursor, Microwave heating, Crystallization, Density

[Received January 9, 2019; Accepted July 29, 2019]

\section{Introduction}

Conventional Solid Oxide Fuel Cells (SOFCs) of operating temperature at around $900^{\circ} \mathrm{C}$ is widely studied because almost whole members are made from ceramics not utilizing rare metals such as platinum and fuels are able to be chosen from not only hydrogen but also hydrocarbons, carbon monoxide, and even carbon. ${ }^{1)-4)}$ SOFCs have these usefulness, on the other hand, reliability and durability are problems because of its high operating temperature. $^{5)-8)}$

Electrolyte thicknesses of electrolyte supported SOFCs were about $150 \mu \mathrm{m}$ to $1 \mathrm{~mm}$ because it must have a certain level of mechanical strength for its self-standing. ${ }^{9)}$ Yttriastabilized zirconia (YSZ) was often used for the electrolyte owing to its high electrical conductivity and hardness. By the thickness of the electrolyte, the resistance of the electrolyte was large, for that reason, high operating temperature was necessary for SOFC system because YSZ presented the low oxide-ion conductivity and high activation energy. ${ }^{9)}$

Due to decrease the electrolyte resistance, SOFCs with thin film electrolyte layer have attracted attention over the years. ${ }^{10), 11)}$ Operating temperature could be decreased at

Corresponding author: M. Yoshinaga; E-mail: yoshinaga@ tokai-u.jp

¥ Preface for this article: Dol http://doi.org/10.2109/jcersj2. 127.P6-1 the range of intermediate temperature around $600^{\circ} \mathrm{C}$ by the thin film electrolyte. The low operating temperature could be utilized of low cost metallic interconnects and decrease the thermal stresses and reduce the reaction products.

High temperature at about $1400^{\circ} \mathrm{C}$ was necessary to be crystallization and sintering for YSZ. When the thin film was generated by the chemical vapor deposition and the Atomic Layer Deposition with the substrate heating, the substrate could not be applied such high temperature because of the durability of the metallic material of the devices. Therefore, the crystallization temperature lower than $1000^{\circ} \mathrm{C}$ was necessary for the YSZ precursors as the thin film electrolyte SOFCs.

Sintering at high temperature when manufacturing flat plate type or tube type SOFC may cause the problem of reaction with the electrolyte to the other parts. When producing SOFC with a thin film electrolyte, the residual stress between the electrode and the electrolyte also becomes a problem. These problems could be avoidable to sinter SOFCs at low temperatures. It is preferring that the precursor powder of the constituent material can be crystallized and sintered at a low temperature.

Homogeneous precipitation method is one of an advanced method for the conventional precipitation methods. This method is utilized for urea as reducing agent with heating, which generates ammonia. More homogeneous precipitation of hydroxide and/or oxide is obtained by the method because the neutralization reaction is occurred everywhere in the solution. However, synthesis of YSZ by 
homogeneous precipitation method has not been reported much because it is in principle difficult that several cations cannot be simultaneously precipitated due to showing inherent degree of solubility for each cation. ${ }^{12)-14)}$

We have been reported that the $8 \mathrm{~mol} \% \mathrm{Y}_{2} \mathrm{O}_{3} / 92 \mathrm{~mol} \%$ $\mathrm{ZrO}_{2}$ (8YSZ) precursor by homogeneous precipitation method with microwave heating could crystallize at lower temperature in shorter time than that with the conventional heating by using autoclave reactor. ${ }^{12)}$ However, detail of precursor and general versatility of this synthesis method for other yttria content YSZ are still unclear. Knowledge concerning general versatility of the present synthesis method can also be expected to contribute to the fields of thin film fuel cells, capacitors and all solid lithium batteries. In this study, the precursors of $x \mathrm{~mol} \% \mathrm{Y}_{2} \mathrm{O}_{3} /$ $(100-x)$ mol\% $\mathrm{ZrO}_{2}(x=3,5,8,10,13)$ were prepared by that method due to the investigation of the general versatility. In addition, the crystalline behavior for yttria contents was investigated by X-ray diffraction (XRD), Raman spectroscopy, and differential scanning calorimetry (DSC).

\section{Experimental}

YSZ precursor powder were prepared by urea homogeneous precipitation method with microwave irradiation. $\mathrm{Y}_{2} \mathrm{O}_{3}$ powder (Wako, reagent grade, $99.9 \%$ ) was dissolved into nitric acid (Wako, special grade, 60\%). $\mathrm{ZrOCl}_{2} \cdot 8 \mathrm{H}_{2} \mathrm{O}$ powder (Wako, reagent grade, 99.0\%) was dissolved into distilled water and then both solutions were mixed as the total cation concentration of $0.3 \mathrm{M}$ adjusted by deionized water and then urea was added into the solution. The solution in the autoclave reactor, containing the cation and urea in a 1:4 mole ratio, was heated by microwave irradiation $(2.45 \mathrm{GHz}, 500 \mathrm{~W})$ for $7 \mathrm{~min}$ using by Shikoku Instrumentation CO., LTD., SMW-060. The autoclave reactor, PFADJ-0120-02, was made from perfluoroalkoxy alkanes by WINTEC. The water in the autoclave can be heated to $118.5 \pm 2.5^{\circ} \mathrm{C}$ within $7 \mathrm{~min}$ by microwave irradiation, which was monitored by a heat label (MICRON Corp., 6R-99). The maximum internal pressure of the autoclave was less than $0.5 \mathrm{MPa}$. The ion ratios of Zirconium/ Yttrium in the precursor solution were adjusted for $97 / 6$, 19/2, 23/4, 9/2, 87/26 which were named as 3YSZ, 5YSZ, 8YSZ, 10YSZ and, 13YSZ, respectively. After microwave irradiation, white precipitation was obtained, then washed and centrifuged by distilled water at $4000 \mathrm{rpm}$ then dried over $12 \mathrm{~h}$ at $85^{\circ} \mathrm{C}$. Crystallization of the precipitation underwent at $500^{\circ} \mathrm{C}$ for $5 \mathrm{~h}$ in the static air. For comparison, specimens of conventional heating process were also carried out in the stainless autoclave. At $100^{\circ} \mathrm{C}$ for $5 \mathrm{~h}$, no precipitation was obtained. At $120^{\circ} \mathrm{C}$ for $5 \mathrm{~h}$, precipitate was obtained clearly. The precipitate crystallized in the same manner as the microwave heating.

Crystallization behavior and crystal structure of the precursors and the specimens were investigated by XRD Bruker Corp. D8 DISCOVER, Raman spectroscopy HORIBA Ltd. XploRA, and Fourier Transform Infrared Spectroscopy (FT-IR) Shimadzu Corp. FTIR-8400.
Calorimetric studies of crystallization were estimated by DSC Shimadzu Corp. DSC-50. DSC measurements were carried out until $500^{\circ} \mathrm{C}$ from room temperature. Heating and cooling rates were $10^{\circ} \mathrm{C} / \mathrm{min}$.

Particle size and morphology of the precursors and the specimens were measured by Field Emission Scanning Electron Microscope (FE-SEM) JEOL Ltd. JSM-7100F.

Sintering performances were evaluated from absolute density of the sintered pellets. The absolute density was bulk density calculated from the volume and weight of the pellets. The specimens after drying at $85^{\circ} \mathrm{C}$ was shaped into pellet of $\phi 10 \mathrm{~mm}$ by uniaxial pressing under $20 \mathrm{MPa}$ for the density evaluation. The evaluation was carried out at room temperature after heat treatments at 500 to $1200^{\circ} \mathrm{C}$ each $100^{\circ} \mathrm{C}$.

\section{Results and discussion}

Figure 1(a) shows the SEM image of the 8YSZ precursor powder by the microwave heating. The shape of the precursor particle was a roundish cuboid, which was agglomerated. The primary $8 \mathrm{YSZ}$ precursor particle size was around $300 \mathrm{~nm}$. Figure 2(a) shows the SEM image of the $8 \mathrm{YSZ}$ precursor powder by the conventional heating. The shape of the $8 Y S Z$ precursor by the conventional
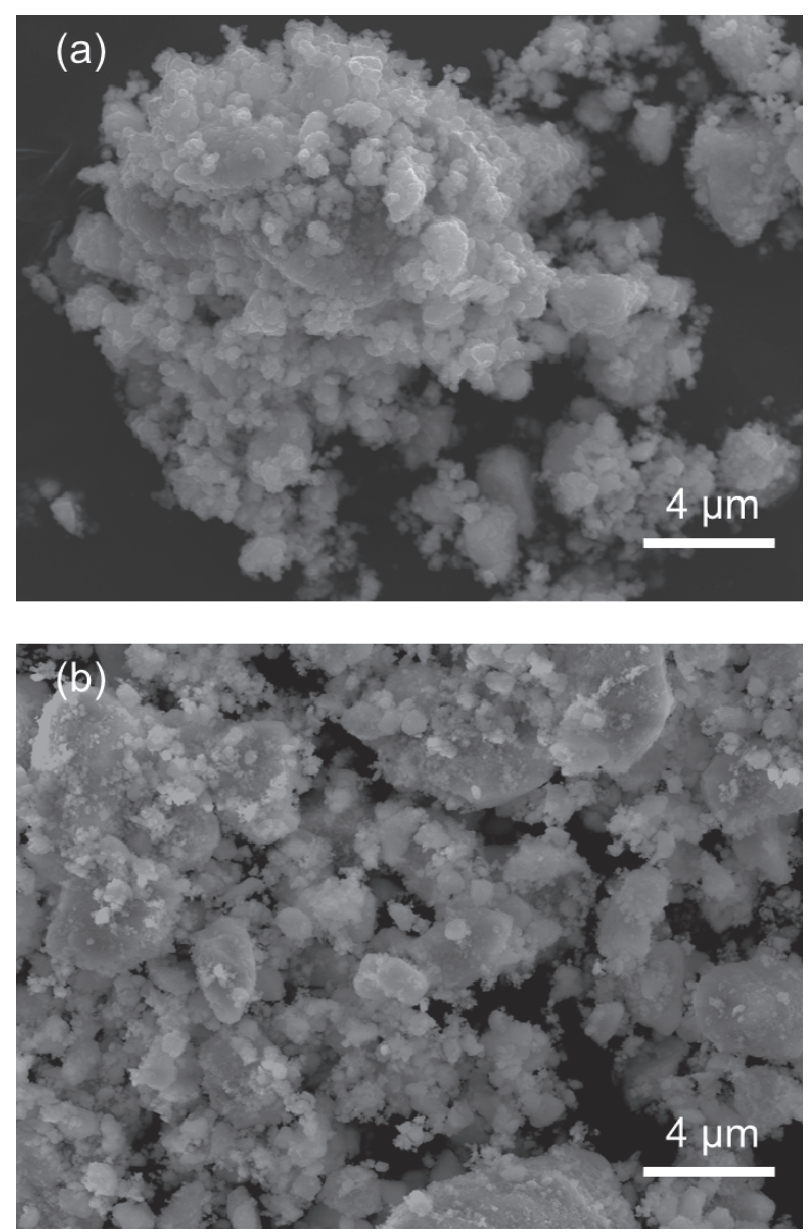

Fig. 1. SEM of (a) the $8 \mathrm{YSZ}$ precursor powder by the microwave heating and (b) the powder after heat treatment at $500^{\circ} \mathrm{C}$ for $5 \mathrm{~h}$. 

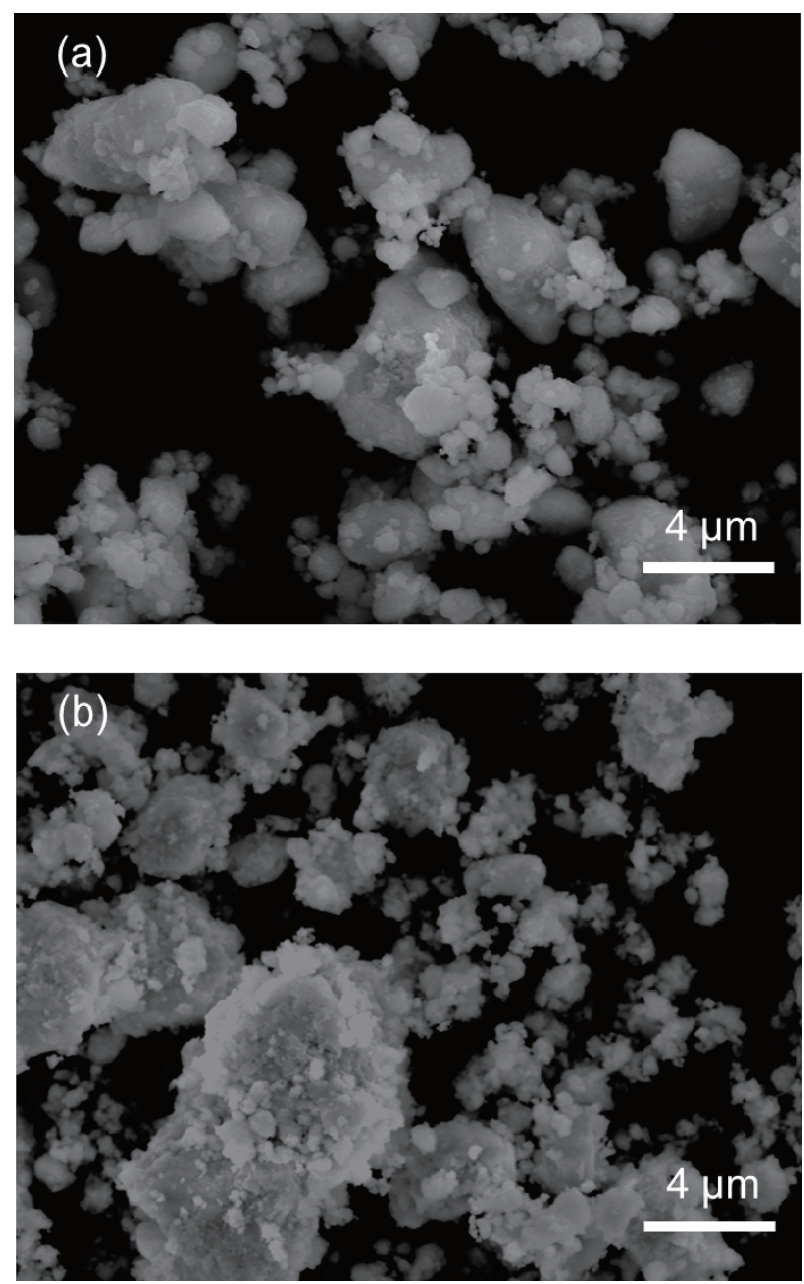

Fig. 2. SEM of (a) the 8YSZ precursor powder by the conventional heating and (b) the powder after heat treatment at $500^{\circ} \mathrm{C}$ for $5 \mathrm{~h}$.

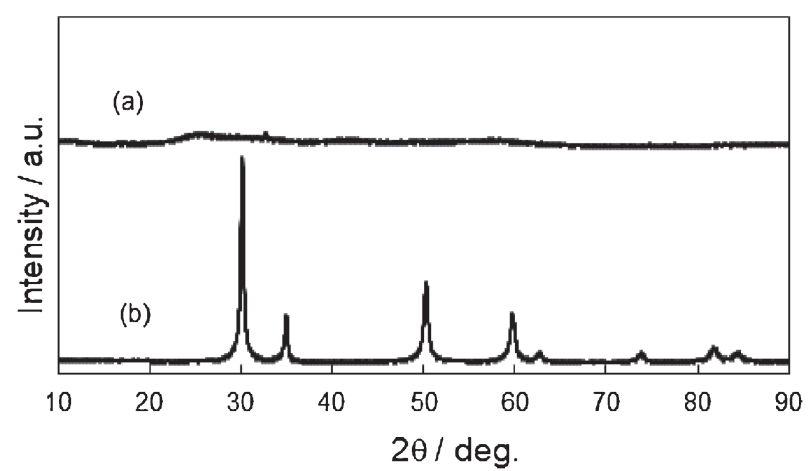

Fig. 3. XRD patterns of (a) the $8 \mathrm{YSZ}$ precursor powder by microwave heating and (b) after heat treatment at $500^{\circ} \mathrm{C}$ for $5 \mathrm{~h}$.

heating was more rotund than that by the microwave heating. The primary particle size was distributed from 0.2 to $1.5 \mu \mathrm{m}$. Figure 1(b) shows the SEM of the $8 \mathrm{YSZ}$ powder after heat treatment at $500^{\circ} \mathrm{C}$. The wide particle distribution was observed that the width was from $10 \mathrm{~nm}$ to several microns. The shape and size for the conventional heating one was almost the same manner as shown in Fig. 2(b).

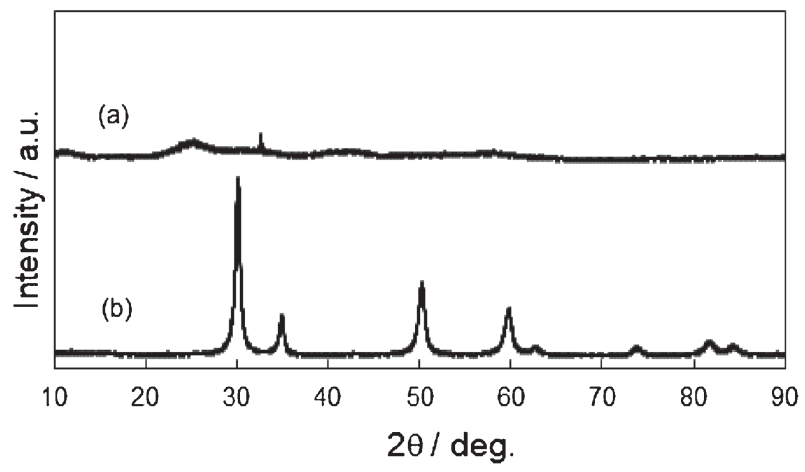

Fig. 4. XRD patterns of (a) the $8 \mathrm{YSZ}$ precursor powder by conventional heating and (b) after heat treatment at $500^{\circ} \mathrm{C}$ for $5 \mathrm{~h}$.

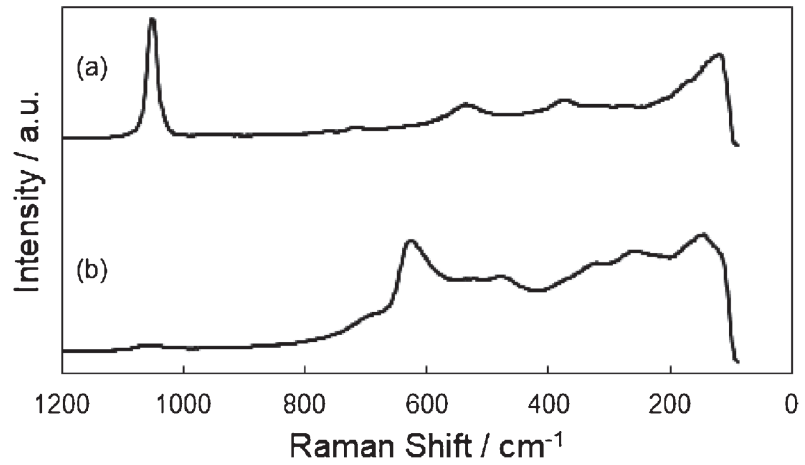

Fig. 5. Raman spectra of (a) the $8 \mathrm{YSZ}$ precursor powder by microwave heating and (b) after heat treatment at $500^{\circ} \mathrm{C}$.

Figure 3 shows the XRD patterns of the 8 YSZ precursor powder by microwave heating and after heat treatment at $500^{\circ} \mathrm{C}$. No peak was observed for the precursor powder as shown in the Fig. 3(a). After heat treatment, the XRD pattern was indexed as a cubic fluorite-type structure as presented in the Fig. 3(b). Figure 4(a) shows the XRD patterns for the $8 \mathrm{YSZ}$ precursor powder by conventional heating. A broad peak at around $25^{\circ}$ and a peak at $32.7^{\circ}$ were observed from the precursor which was consisted with that by the microwave heating. Figure 4(b) shows the XRD patterns of the $8 \mathrm{YSZ}$ by conventional heating after heat treatment at $500^{\circ} \mathrm{C}$. That was almost consistent with the microwave one.

Figure 5(a) presents the Raman spectra of the 8YSZ precursor by microwave heating and the heated specimen at $500^{\circ} \mathrm{C}$. The Raman peaks for the precursor were observed at $374,536,717,1051 \mathrm{~cm}^{-1}$. The Raman peaks at 374 and $536 \mathrm{~cm}^{-1}$ were originated from $\mathrm{Zr}-\mathrm{O}$ vibration in the precursor. ${ }^{15}$ ) The peaks at 717 and $1051 \mathrm{~cm}^{-1}$ were assigned to $\mathrm{Zr}-\mathrm{OH}$ vibration, ${ }^{15)}$ which suggested that the precursor consisted with tetrametric hydroxo-cation $\left[\mathrm{Zr}_{4}(\mathrm{OH})_{8}\left(\mathrm{H}_{2} \mathrm{O}\right)_{x}\right]^{8+} .{ }^{15)}$ After $500^{\circ} \mathrm{C}$ heat treatment, the Raman peak at $626 \mathrm{~cm}^{-1}$ was appeared, shown in Fig. 5(b). This peak was originated from $\mathrm{Zr}-\mathrm{O}$ vibration in the cubic structure. ${ }^{16)}$ Moreover, extremely broad peaks at $154,269,330,486 \mathrm{~cm}^{-1}$ were observed for tetragonal phase of YSZ by Raman spectroscopy, which was not observed by XRD. In the precursor, it suggested that tetragonal crystals appeared because not all $\mathrm{Zr}^{4+}$ and $\mathrm{Y}^{3+}$ 


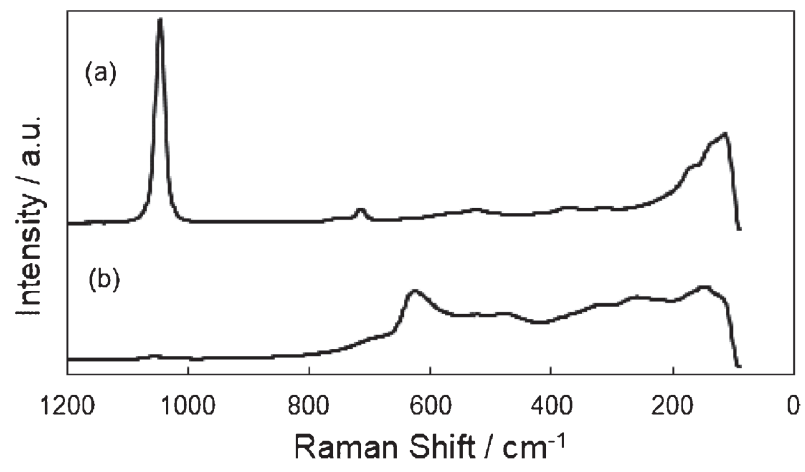

Fig. 6. Raman spectra of (a) the 8YSZ precursor powder by conventional heating and (b) after heat treatment at $500^{\circ} \mathrm{C}$.

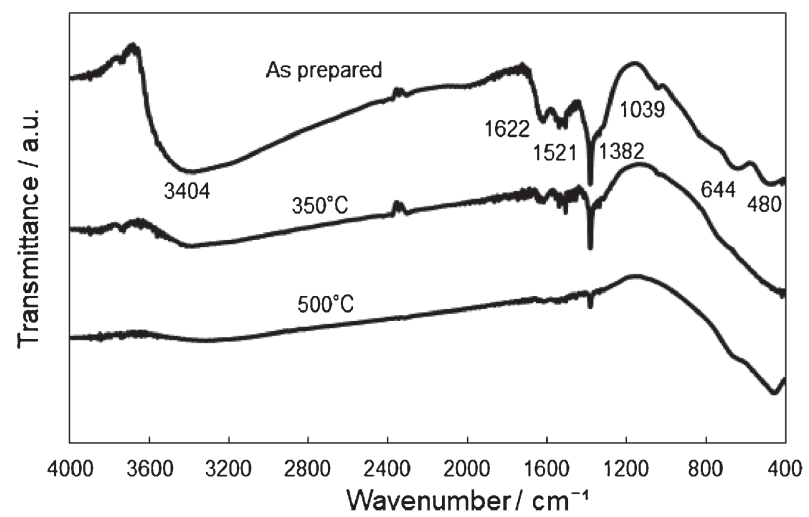

Fig. 7. FT-IR spectra for the as prepared $8 \mathrm{YSZ}$ precursor by microwave heating, after annealing at $350^{\circ} \mathrm{C}$ and $500^{\circ} \mathrm{C}$ in the static air.

bonded. Since it was cubic after crystallization, it was thought that $\mathrm{Y}^{3+}$ was uniformly dispersed in the precursor and that they were mutually bonded after heat treatment.

The Raman spectra of the 8YSZ precursor by conventional heating and the heated specimen at $500^{\circ} \mathrm{C}$ are shown in Fig. 6. For the spectrum of the precursor, peaks were observed at the same wavenumber as that of the microwave heating. The precursor by conventional heating was also essentially same for the microwave heating one. However, for the precursor, peak intensity ratio of $\mathrm{Zr}-\mathrm{O}$ vibration $/ \mathrm{Zr}-\mathrm{OH}$ vibration for conventional heating was lower than that of microwave heating. Figure 6(b) shows the Raman spectrum for the heated specimen at $500^{\circ} \mathrm{C}$. The crystal structure after heating was identified as mixed structure both cubic and tetragonal. ${ }^{16)}$

Figure 7 shows FT-IR spectra for the as prepared precursor by microwave heating, after annealing at 350 and $500^{\circ} \mathrm{C}$ in the static air. As prepared precursor showed the absorption bands assigned to vibration of $\mathrm{Zr}-\mathrm{O}$ bond at about 480 and $644 \mathrm{~cm}^{-1}$. ${ }^{17)}$ The $\mathrm{OH}$ stretching and water hydration were observed at around 3404 and $1623 \mathrm{~cm}^{-1}$, respectively, and also at $1045 \mathrm{~cm}^{-1}$ for $\mathrm{C}-\mathrm{OH}$ bond. ${ }^{18)}$ Bonds at around 1382 and $1521 \mathrm{~cm}^{-1}$ were originated to the vibration from carbonate. ${ }^{17)}$ After annealing at $500^{\circ} \mathrm{C}$, the bonds for $\mathrm{OH}$ stretching, water hydration, $\mathrm{C}-\mathrm{OH}$ and carbonate were disappeared and only appeared $\mathrm{Zr}-\mathrm{O}$ bond

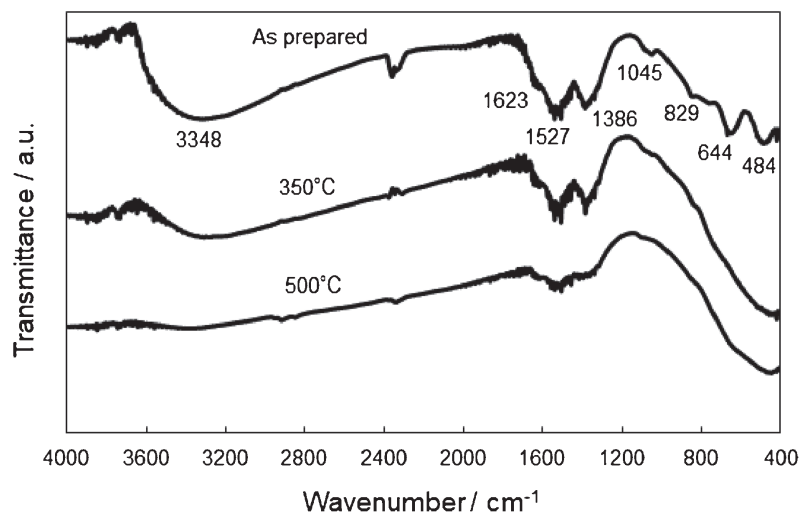

Fig. 8. FT-IR spectra for the as prepared $8 \mathrm{YSZ}$ precursor by conventional heating, after annealing at $350^{\circ} \mathrm{C}$ and $500^{\circ} \mathrm{C}$ in the static air.

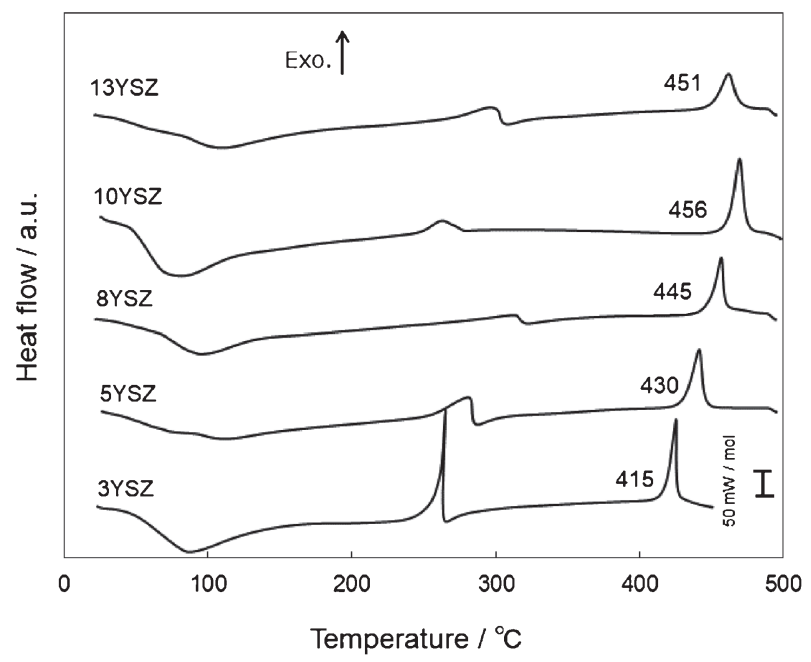

Fig. 9. DSC curves of the specimens by microwave heating for each yttria content during the heating process.

which was assigned tetragonal $\mathrm{ZrO}_{2}{ }^{17)}$ In contrast, conventional heating YSZ after annealing at $500^{\circ} \mathrm{C}$ carbonate bonds still observed as shown in Fig. 8.

Figure 9 shows the DSC curves of the specimens by microwave heating for each yttria content during the heating process. Endothermic broad peaks were appeared at around $100^{\circ} \mathrm{C}$. This was water vaporization from the precursor. An exothermic peak around $250^{\circ} \mathrm{C}$ was observed, which means combustion of organic matter in the specimen as the decomposition of the precursor. The exothermic peak at about $450^{\circ} \mathrm{C}$ was originated from the crystallization of the precursors. The temperatures of water vaporization, decomposition, and crystallization of the precursor were different by the specimens. Figure 10 presents the DSC curves of the specimens by conventional heating. The endothermic broad peaks at about $100^{\circ} \mathrm{C}$ were also observed as water vaporization. The exothermic peaks around $250^{\circ} \mathrm{C}$ were also observed as the decomposition of the precursor. At about $450^{\circ} \mathrm{C}$, the crystallization peak was observed. The results of DSC for conventional heating were basically consisted with that of the microwave heat- 


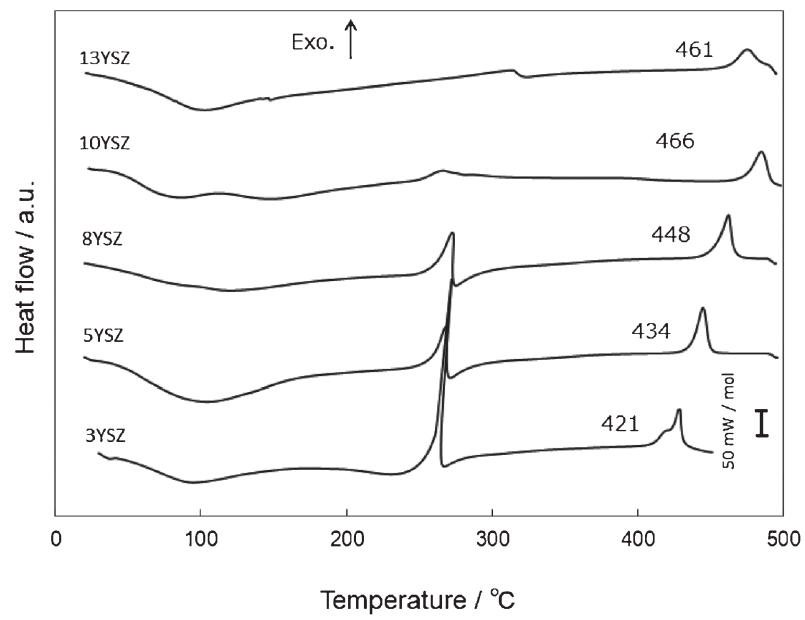

Fig. 10. DSC curves of the specimens by conventional heating for each yttria content during the heating process.

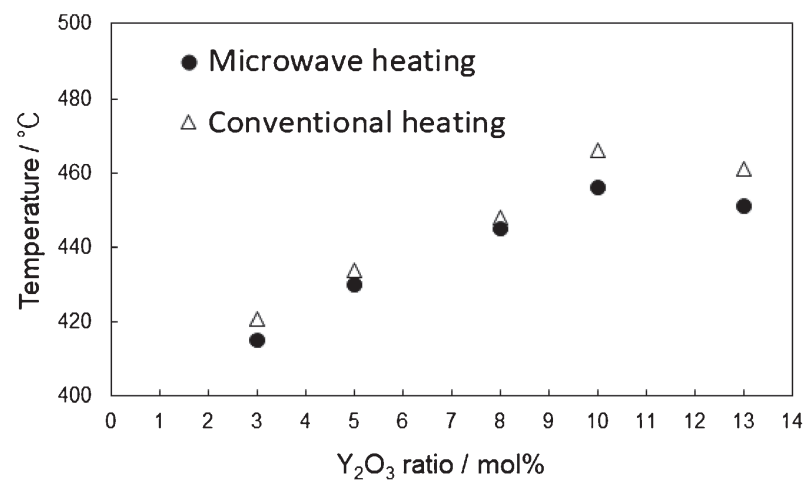

Fig. 11. Crystallization temperatures of the precursors by microwave heating and conventional heating.

ing. Figure 11 shows the crystallization temperatures estimated by the DSC curves. The crystallization temperatures increased with increasing yttria ratio and were lower for microwave heating than that for conventional heating.

We have been reported that the microwave technique can reduce the crystallization temperature. ${ }^{12)}$ In this study, this decrease phenomenon was reappeared for $8 \mathrm{~mol} \%$ yttria, moreover, that was also observed from 3 to $13 \mathrm{~mol} \%$ yttria. It is interesting that an inclination is different between low yttria region from 3 to $8 \mathrm{~mol} \%$ and high region of 10 to $13 \mathrm{~mol} \%$. In the range of 10 to $13 \mathrm{~mol} \%$ of yttria, the crystallization temperatures were more decrease than that in the range of 3 to $8 \mathrm{~mol} \%$. We believe that this difference is caused by generation ratio of crystal structures both cubic and tetragonal.

Figure 12 presents the density of the pellet for the precursors by microwave heating and conventional heating for each yttria content. The density by microwave heating at room temperature was higher than that by conventional one. At 900 and $1000^{\circ} \mathrm{C}$, the density was gently increased according to increase temperature. The density of microwave heating was higher than that of the conventional one in this range. This difference of the sinterability could be coused by microwave heating.

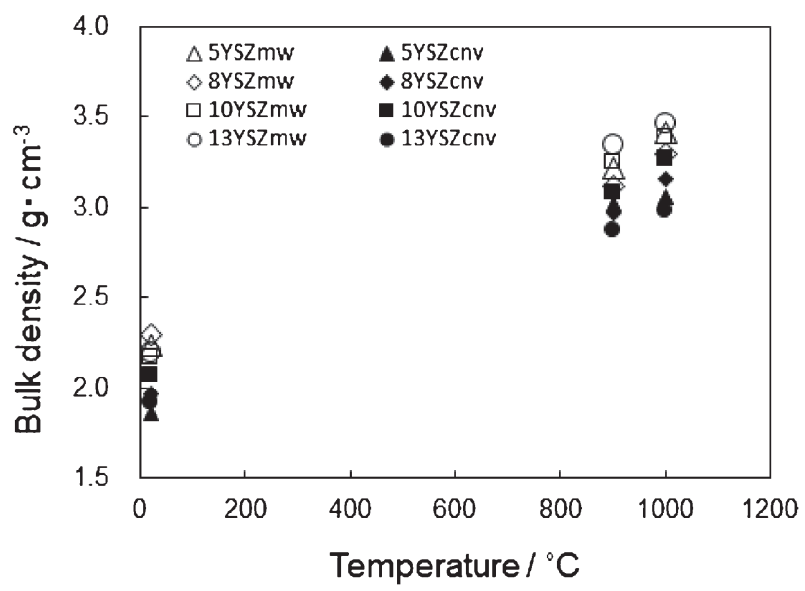

Fig. 12. Density of the pellet for the precursors by microwave heating and conventional heating for each yttria content.

\section{Conclusion}

The YSZ precursors of $x$ mol\% $\mathrm{Y}_{2} \mathrm{O}_{3} /(100-x) \mathrm{mol} \%$ $\mathrm{ZrO}_{2}(x=3,5,8,10,13)$ could be successfully synthesized by homogeneous precipitation method with microwave heating. The precursor was found to be containing zirconium hydroxide by Raman spectroscopy. By the DSC measurements revealed that the crystallization temperatures for the microwave heating was smaller than those for the conventional heating. For high yttria content YSZ above $10 \mathrm{~mol} \%$, the crystallization temperatures were more decrease than those of the lower yttria content. For microwave heating, the crystallization temperature of the precursor was lower, and the density was higher than that of conventional heating. This advance could cause by microwave technique.

Acknowledgement This study was supported in part by a general incorporated association of KOGANEI SEIKI, and Technology Joint Management Office in Tokai University.

\section{References}

1) S. Assabumrungrat, N. Laosiripojana, V. Pavarajarn, W. Sangtongkitcharoen, A. Tangjitmatee and P. Praserthdam, J. Power Sources, 139, 55-60 (2005).

2) D. Singh, E. H. Pacheco, P. N. Hutton, N. Patel and M. D. Mann, J. Power Sources, 142, 194-199 (2005).

3) M. Homel, T. M. Gür, J. H. Koh and A. V. Virkar, J. Power Sources, 195, 6367-6372 (2010).

4) Y. Tang and J. Liu, Int. J. Hydrogen Energ., 35, 1118811193 (2010).

5) H. Yokokawa, T. Horita, N. Sakai, K. Yamaji, M. E. Brito, Y.-P. Xiong and H. Kishimoto, Solid State Ionics, 117, 3193-3198 (2006).

6) T. Horita, Y.-P. Xiong, H. Kishimoto, M. E. Brito and H. Yokokawa, J. Electrochem. Soc., 157, B614-B620 (2010).

7) H. Kishimoto, N. Sakai, K. Yamaji, Y.-P. Xiong, M. E. Brito and H. Yokokawa, Solid State Ionics, 179, 20372041 (2008).

8) C. M. Chun, D. J. Mumford and T. A. Ramanarayanan, J. Electrochem. Soc., 147, 3680-3686 (2000). 
9) A. Weber and E. I. Tiffée, J. Power Sources, 127, 273283 (2004).

10) C. D. Baertsch, K. F. Jensen, J. L. Hertz, H. L. Tuller, S. T. Vengallatore, S. M. Spearing and M. A. Schmidt, J. Mater. Res., 19, 2604-2615 (2004).

11) S. J. Litzelman, J. L. Hertz, W. Jung and H. L. Tuller, Fuel Cells, 5, 294-302 (2008).

12) T. Mitsumori, K. Yano, R. Fujihara, K. Sasaki and M. Yoshinaga, J. Ceram. Soc. Jpn., 123, 359-362 (2015).

13) S. Sohn, Y. Kwon, Y. Kim and D. Kim, Powder Technol., 142, 136-153 (2004).
14) X. Xin, Z. Lü, Z. Ding, X. Huang, Z. Liu, X. Sha, Y. Zhang and W. Su, J. Alloy. Compd., 425, 69-75 (2006).

15) P. D. Southon, J. R. Bartlett, J. L. Woolfrey and B. B. Nissan, Chem. Mater., 14, 4313-4319 (2002).

16) H. Kishimoto, K. Yashiro, T. Shimonosono, M. E. Brito, K. Yamaji, T. Horita, H. Yokokawa and J. Mizusaki, Electrochim. Acta, 82, 263-267 (2012).

17) Y. Gao, Y. Masuda, H. Ohta and K. Koumoto, Chem. Mater., 16, 2615-2622 (2004).

18) P. R. Arya, P. Jha and A. K. Ganguli, J. Mater. Chem., $13,415-423$ (2003). 